\title{
Using Emergence Theory-Based Curriculum to Teach Compromise Skills to Students with Autistic Spectrum Disorders
}

\author{
Lance Fein, Ed.D. \\ Walden University \\ Don Jones, Ed.D. \\ Texas A\&M University - Kingsville
}

\begin{abstract}
This study addresses the compromise skills that are taught to students diagnosed with autistic spectrum disorders (ASD) and related social and communication deficits. A private school in the southeastern United States implemented an emergence theory-based curriculum to address these skills, yet no formal analysis was conducted to determine its effectiveness. Guided by cognitive development and constructivist theories, a concurrent, mixed methods, case study design was used to investigate the impact of this curriculum on teaching compromise skills to middle school students with ASD and related deficits. For the qualitative sequence, teacher observations and compromise interventions from eight participants were open coded and analyzed thematically. The frequency of each thematic occurrence was analyzed using descriptive statistics. For the quantitative sequence, an ANCOVA and descriptive statistics were used to analyze posttest scores between a treatment group that used emergence theory-based curriculum and a control group, while controlling for pretest scores. Three most frequently occurring themes emerged regarding teachers' need (a) to understand the cognitive deficits exhibited by students, (b) for further instruction in emergence theory-based curriculum, and (c) for opportunities to plan lessons together using emergence theory. Moreover, the ANCOVA revealed a significant interaction between the pretest scores and the curriculum used. This study indicated that importance for remediating cognitive deficits related to compromise within the population of students with ASD and improving educator understanding and success in working with this student population.
\end{abstract}

Keywords: autistic spectrum disorders, emergence theory-based curriculum, teaching compromise skills, ASD Compromise, emergence theory

FEIN \& JONES / DOI: 10.5929/2015.5.1.4 
T his study examined the effects of emergence theory-based curriculum as a method of teaching compromise skills to students with ASD. Compromising requires the ability to settle differences by concession and to intermediate or blend qualities of two or more ideas or things. Teaching students with ASD to understand other points of view and then include these perspectives in their decision making is critical to their long-term success.

Students with ASD have difficulty compromising because their brains interpret everything literally, and their perspectives of the world are black and white, with no room for grey areas (Rucklidge, 2009). This inability to compromise creates a multitude of problems for students with ASD within and without the school setting (Hui Min \& Lay Wah, 2011). The art and importance of compromise cannot be understated. Compromising is a critical skill that facilitates progress and relationships where there would otherwise be dead ends and voids (Ferlazzo, 2011). Teaching the art and skills of compromise to students with ASD might provide them with the additional communication skills and strategies necessary for social success. However, teaching these skills is not a simple task. Students with ASD also are characterized by fixed interests with abnormal intensity, excessive adherence to routine, and resistance to change (American Psychiatric Association [APA], 2012). These students show little to no interest in student discussions and often are ostracized from the group, left out of conversations, and are teased or bullied. Van Roekel (2010) found that adolescents with ASD are more likely to be bullied and are involved in more incidents of bullying at school than students without ASD are.

Successfully integrating students with ASD and their peers is a challenge facing all schools, especially public schools. Private schools have the right to refuse admission to students with ASD, but public schools are required by federal law to provide all students with the least restrictive educational environment, leading to the placement of many students with ASD in inclusion or mainstream classrooms within the public school system (U.S. Department of Education, 2004). Most students with ASD are not aggressive or violent, so they are placed in mainstream classrooms with accommodations or support; however, finding ways to include students with ASD in the mainstream classroom setting remains a global problem.

The lack of training and in-services for teachers of students with ASD is another contributing factor to the larger problem of social integration. Morrier, Hess, and Heflin (2011) studied ASD teacher training in a southern state of the United States. The teachers reported that training was selected based upon an online survey and that the most common training was attendance at a half-day or a full-day workshop. The teachers also commented on the lack of exposure to research-based or evidence-based practices. Furthermore, only $15 \%$ of the teachers had received training from teacher preparation programs at colleges or universities (Morrier et al., 2011). Without proper educator training, it is difficult, if not impossible, to achieve the appropriate and successful social integration of students with ASD within the school setting. Differentiated instruction is successful only for academic achievement; differentiated social instruction is necessary for social achievement and compromise skills development within the classroom setting.

Successfully integrating students with ASD with students who do not have ASD is challenging because their social skill deficits hinder appropriate peer-level conversations and interactions (Hussin, Cheong, \& Ai Hwa, 2012; Jones \& Fredrickson, 2010). These difficulties permeate all levels of the daily operations of 
PNSUS and its alternative schools behaviorally, academically, and socially. Many of the confrontations between students with ASD and students who do not have ASD are based upon incorrect perceptions and the inability to compromise (PNSUS principal, personal communication, March 5, 2013). Furthermore, students with ASD do not derive the benefits of forming meaningful friendships and seldom engage in social bonding during school.

The lack of integration between students with ASD and students who do not have ASD at school creates an environment in which students with ASD are not exposed to age-appropriate peer relations. Lawhon and Lawhon (2000) asserted that because friendships are vital to healthy childhood development, children who do not develop the appropriate skills to acquire and maintain friendships are more likely to suffer from mental illness, health problems, and personality disturbances in adulthood. These childhood friendships are forged primarily at school with classmates.

A private, nonprofit school in the southeastern United States (PNSUS) operates several alternative schools, and many of the children and adolescents attending these schools have been diagnosed with ASD and/or related communication and social deficits. One of these schools caters to students of average to above-average intelligence who are not successful in the traditional school setting. The school has a population of 210 students, including a middle school population of 75 students in Grades 6 to 8. Despite their intelligence, many of the students do not test well and are subsequently not successful in traditional schools. The severity and range of ASD symptoms vary greatly: some individuals present with intelligence quotients (IQs) below 80 and are considered mentally retarded (MR), whereas others score in the genius range (Healy, 2008). These same students have social deficits and language problems that result in social or behavioral difficulties, be it in the home environment or elsewhere. They also have difficulty starting, building, and maintaining friendships. Many of the students who attend the school have been diagnosed with ASD, including autism, Asperger's syndrome (AS), pervasive developmental disorder (PDD), and comorbidity with ADD/HD. Beyond the actual diagnosis, these children are characterized by their inability to see other points of view and an impaired ability to symbolize when communicating and during play (Morris, 2008).

The majority of students who attend PNSUS were enrolled in the public school system for several years prior to seeking private education. Public school and mainstream curricula do not provide social skill or life skill remediation to students with ASD. This lack of remediation within the public system has increased the demand and attendance at PNSUS: the school grew from 23 students in 2003 to 180 students in 2014. The growth at PNSUS has mirrored the expansion of ASD in the general population. According to the Centers for Disease Control and Prevention (21013), a diagnosis of ASD has risen from one in 2,000 to one in 68 over the past 30 years. Although changes in diagnostic criteria might be partially responsible for the increase in ASD, there is no question of the escalating prevalence of ASD in the general population (Yeargin-Allsopp, 2003).

Public school curriculum does not include teaching social and life skills to students (PNSUS principal, personal communication, March 5, 2013). Students with ASD who are enrolled in public school are given academic assistance, including tutors and individual aids in the classroom. Nonacademic interventions range from installing FM systems to outfitting students with ASD with weighted vests and ankle weights in order to reduce fidgeting and improve their focus on learning. However, none of the accommodations 
accounts for or remediates the social deficits of the students (Hodgetts, 2011). If not remediated, these social deficits continue through adulthood, when the majority of adults with ASD begin to receive services through Medicaid. Mandell, Coa, Ittenbach, and Pinto-Marin (2006) found that the costs of providing services to adults with ASD has increased eightfold over the last 20 years and that the cost of assistance for adults with ASD was 3 times greater than the cost of assistance to adults with MR.

The Individuals with Disabilities Education Act (IDEA, 2004) governs the placement and treatment of students with ASD within the public school. Researchers have identified socialization as an essential consideration because it is the main deficit of ASD. Horrocks et al. (2008) noted that students with ASD have little experience developing peer relations and that regular education students are not prepared to accept, understand, or empathize with them. They also concluded that inclusion attempts are likely to fail and that most educators feel that they are not equipped to meet the social and behavioral needs of students with ASD. Changing these perceptions and finding ways to integrate students with ASD into the mainstream student population successfully is crucial to the long-term success of the population with ASD.

Historically, educational practices for children with ASD have been compromised by conflicts in approaches and significant differences in theory (Quill, 1995). In recent years, educational strategies for ASD have become less dogmatic and more focused on theory and best practices. Goals for intervention focus on enhancing the communication and socialization abilities of individuals with ASD, with the outcomes being better conflict resolution, stronger decision-making skills, and active participation with peers (Fletcher-Watson, McConnell, Manola, \& McConachie, 2014; Quill, 1995). Teaching students with ASD to compromise would reinforce and require a plethora of social and cognitive skills. Children need to experience success in the various social contexts of their lives: school, home, and daily interactions. This success sets the foundation for additional learning and creates stronger self-esteem. Without effective communication skills, social, personal, and career success are hindered (Lawhon \& Lawhon, 2000).

\section{HISTORICAL BASIS}

According to Lewes (as cited in Goldstein, 1999), believing that the results are either the sum or the difference of forces, depending on whether the forces are cooperative or contrary, is not sufficient. Lewes claimed that the components cannot be broken down into their respective parts or differences. Lewes found that emergents could not be accounted for because the sum of the components not only contained individual components, but also produced emergents that were not the expected result of combining one or more components and had no relation to the original components.

Emergence theory can be found in a wide array of sciences, including chemistry. In 1843, Mill proved that the chemical combination of two substances produces a third substance whose properties are different from either of the two separately or both taken together. Similar to synergy, emergence theorists have stated that the whole is greater than the sum of the parts, as well as more complex, dynamic, and structured. According to emergence theory, the most complex structures and patterns develop from the self-organization of simple processes (Hotton \& Yoshimi, 2011). Emergence theory is present in the fields of psychology, physics, economics, and evolution. The use of emergence theory 
helps to explain hurricanes, traffic congestion, ecosystems, and complex organisms (Szameitat et al., 2010). Emergence theory was built on the framework that establishing a few simple rules that every part of a system can follow produces highly complex behaviors and results.

Despite the acceptance of emergence theory among scientists, the theory has not been applied to teaching compromise and communication skills. Ablowitz and Goldstein (2010) defined emergence as novel patterns and properties arising from the self-organizing efforts of simple and complex systems. Communication is a complex activity encompassing words, vocabulary, and sounds; intonation; body language; volume; facial expressions; and the ability to understand, process, and respond appropriately. Designing a curriculum based upon emergence theory might be a potential solution to teach complex communication skills to children and adolescents with ASD and, ultimately, give them the ability to learn compromise skills.

\section{THEORETICAL FRAMEWORK}

Emergence theory has evolved over time and has been incorporated into other social and cognitive development theories. Butt (2008) noted that emergence theory was based upon Piaget's (1951) theory of cognitive development and biological intelligence, Skinner's (1977) theory of behaviorism, and Vygotsky and Vygotsky's (1980) theory of social cognition. These three theories answer the respective questions of when, why, and how people learn (Butt, 2008).

\section{CASE STUDY DESIGN}

The design incorporated deidentified quantitative data from student assessments and deidentified qualitative data from teachers' observations of students, student summaries of events, and teacher feedback. According to Yin (2005), case studies can include qualitative and quantitative data, and "both types of data can be highly complex, demanding analytic techniques going well beyond simple tallies" ( $p$. 388). Case study research is generally qualitative, but it also can incorporate quantitative results (Yin, 2009). Yin (2005) noted that quantitative data can be relevant to case studies for several reasons; namely, the data can help to explain the outcomes. Yin also commented that the data could be related to an embedded "unit of analysis" (p. 133) within a broader case study that would require the use of qualitative and quantitative data.

PNSUS collected the quantitative data as pretesting and posttesting of the students using the TOPS 2, a preestablished, standardized instrument designed to assess students' language-based thinking strategies using experience and logic. The test addresses critical-thinking skills based upon language in the areas of predicting, sequencing, problem solving, making inferences, proposing negative questions, and determining causes (Huisingh \& LoGiudice, 2005).

Measuring the effect of the emergence theory-based curriculum implemented at PNSUS required data from students and teachers. The social skill deficits of the students did not allow for reliable or valid qualitative feedback from their perspectives; therefore, qualitative feedback was obtained through summary notes of teachers who observed the students. All teaching staff were exposed to an 
emergence theory-based curriculum through a PD in-service session. The teaching staff also participated in emergent-based activities and games to augment their understanding of this curriculum.

\section{Data Approach}

The quantitative data were obtained by PNSUS from students selected by the principal from five middle school classrooms. Three classes (Classes A, B, and C) served as the treatment group, and two classes (Classes D and E) served as the control group. PNSUS exposed the students in the treatment group to the new emergence theory-based curriculum, but it had not implemented the emergence theory-based curriculum in all classrooms, so the research design facilitated the use of control and treatment groups in the study. The initial data collected were a quantitative assessment of all students using the TOPS 2, a preestablished, standardized instrument. The data were used the data to obtain a quantitative baseline, and the initial assessment represented the pretesting data. The school readministered the TOPS 2 upon completion of the emergence theory-based curriculum; the results represented the posttesting data.

\section{Quantitative Sequence of Design}

The quantitative data were obtained from the TOPS 2, which has six subtests: making inferences, predicting, determining causes, sequencing, proposing negative questions, and problem solving. Data collected from the TOPS 2 assessment were used to determine the effectiveness of the emergence theory-based curriculum. There is no standardized measurement of compromise, but the TOPS 2 assesses the underlying cognitive skills required for compromise. Therefore, it was assumed that the ability of the participants to compromise would correlate with their TOPS 2 test scores.

\section{Qualitative Sequence of Design}

The middle school teachers who participated in this study directly observed students during implementation of the emergence theory-based curriculum. Besides making observations during specific class times designated to the curriculum, teachers also made direct observations of the students' social interactions throughout the day. During the day, teachers qualitatively documented any incidents with students through written summaries and provided a solid base of qualitative data which could be chronologically referenced. The data were used to (a) determine whether the number of negative reports diminished during the curriculum implementation period and (b) develop themes, guide research, and help to test the hypothesis.

Additional qualitative data were collected (i.e., agendas and summaries) during staff meetings with teachers and administration. These scheduled meetings focused on updating administration on curriculum implementation, sharing ideas among the teachers on effective methods of teaching, updating staff on general housekeeping issues, and providing a forum to collect feedback on any observable changes in student behaviors toward other students and teachers. The principal deidentified students and teaching staff prior to distribution of the notes and maximized the protection of all participants. 


\section{SETTING AND SAMPLE}

The sample for this case study comprised students diagnosed with ASD or related social and communication deficits. The target population was PNSUS middle school (Grades 6-8) students with ASD. These middle school classrooms are representative of the general population of the school, as well as the overall general population of children and adolescents diagnosed with ASD. The school enrolls students from public and private schools, is nondenominational, and serves a diverse student body.

Many research projects use nonprobability sampling to meet chosen criteria or simply for the sake of convenience. Typically, researchers use convenience sampling when there are readily available groups of individuals (Henry, 1990; Lee-Jen Wu, Hui-Man, \& Hao-Hsien, 2014). PNSUS identified the middle school groups that were going to use the emergence theory-based curriculum, and therefore convenience sampling was the best fit for this case study.

PNSUS regularly implements new and creative curriculum content. PNSUS employed an emergence theory-based curriculum in various middle school classrooms for 12 weeks. The 58 participants were from five middle school classrooms. Students in the three classrooms selected to receive the emergence theory-based curriculum comprised the treatment group; students in the two classrooms not selected comprised the control group (see Table 1).

Table 1

Group Identifiers and No. of Participants

\begin{tabular}{cc}
\hline \multicolumn{1}{c}{ Group Identifier } & No. of Participants \\
\hline Treatment Group & \\
Classroom A & 13 \\
Classroom B & 10 \\
Classroom C & 10 \\
Control group & \\
Classroom D & 14 \\
Classroom E & 11 \\
Combined treatment & 33 \\
Combined control & 25 \\
Combined total & 58 \\
\hline
\end{tabular}

All students enrolled at the school were eligible to participate in this study. The selected student sample comprised average to above-average functioning middle school students diagnosed with ASD and other social or communication deficits. PNSUS considers students average to high functioning if they are selfsufficient in areas of hygiene, dressing, and feeding; are toilet trained; are literate; and show proficiency in spoken language. All students at PNSUS are screened prior to admission to ensure that they meet these criteria. The selected teacher sample comprised all middle school teachers and any support staff working with middle school students at PNSUS. All of the middle school teachers had worked at PNSUS 
for at least 1 year, with an average tenure of 8 years. They were familiar with the systems at PNSUS and had implemented and assessed several pilot programs throughout the years.

\section{DATA ANALYSIS AND VALIDATION}

All deidentified data was analyzed at the end of the 12-week emergence theory-based curriculum implementation. Statistical analysis of quantitative data was performed by comparing the pretest and posttest results for significance. Qualitative feedback from the teachers regarding student interactions proved meaningful and revealed changes in compromise skills and consensus skills that could not be measured quantitatively.

\section{Qualitative Results}

The complete set of qualitative data provided included 329 student TRIC sheets and two staff meeting summaries generated over the 12-week emergence theory-based curriculum implementation, 2 weeks pre implementation, and 2 weeks postimplementation. The TRIC data were read multiple times to gain insight into the events surrounding why students had been asked to leave the class or had requested to leave the classroom or assigned area. According to Creswell (2012), qualitative data analysis begins by grouping similar text segments or responses. The TRICS containing similar responses or text segments were grouped. The coding process involves labeling and segmenting these data into broad themes (Creswell, 2012). During the coding process, like responses and similar segments of texts were grouped.

Initial coding notes included whether the students were sent by teachers or had requested to leave. A second round of coding identified whether the students had behavioral issues with other students or were not complying with teacher or class rules. A final round of coding identified incidents in which students had issues involving more than one person, which were then identified as group issues. Finally, incidents in which the students were aggressive were identified. Similar incidents were ultimately chosen to align with the perspectives of the students. Ultimately, five major themes developed (see Figure 1) based upon the teachers' reports and students' perspective as to why they had been asked to leave the class:

- B (Behavior): Student was involved in a behavioral incident with another student.

- T (Teacher sent): Student was asked to leave the classroom for being disruptive or noncompliant.

- $S$ (Self-sent): Student requested to leave the classroom.

- $\quad G$ (Group incident): Student had an issue with two or more other students.

- A (Aggression): Student exhibited aggressive or threatening behavior. 


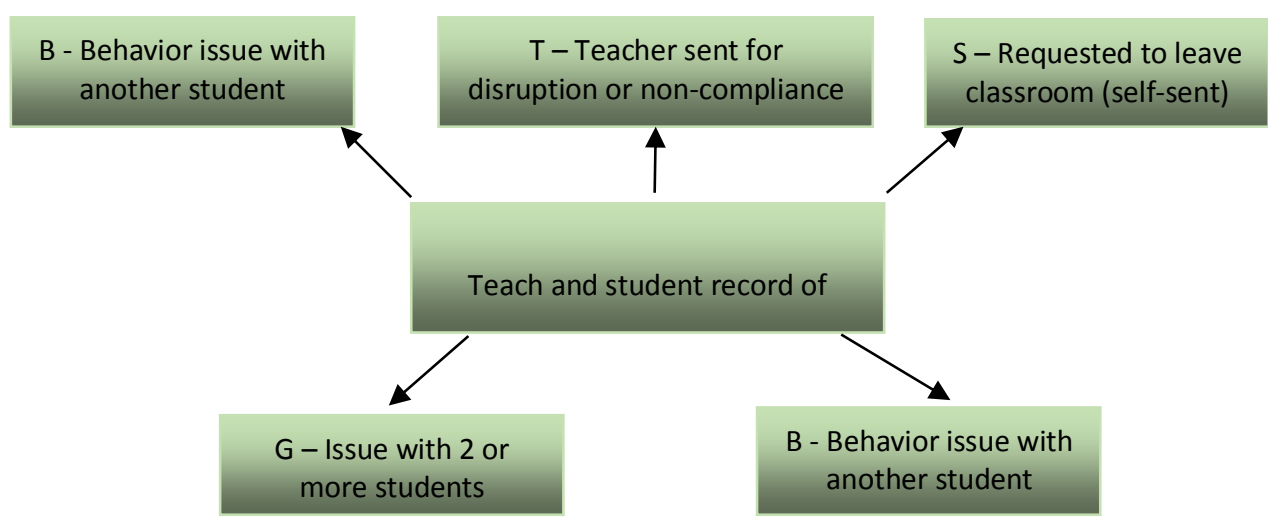

Figure 1. Qualitative themes.

Each TRIC sheet was labeled with one of the themes, sorted by student identifiers (class and number), and then sorted again within identification numbers by date. The occurrence of each incident was entered into an Excel spreadsheet. The letter B, T, S, G, or A was entered into the cell corresponding to the student identification number and the date of the incident. Table 2 is a sample of the Excel sheet used to enter the occurrences of the themes developed during the qualitative data analysis. Tables 3 and 4 are examples of Group A's first-half and second-half frequencies.

Prior to analyzing the coded themes, the principal reviewed the coded TRICS and provided feedback about any coding themes that might have fit better into a different theme than the code assigned by author. This form of peer review helped to ensure that the coded themes developed from the qualitative data were identified accurately. Descriptive statistics were performed on the qualitative data as a whole without accounting for group differences. The frequency of each occurrence was measured during the first 55 days $(55 \mathrm{~A})$ of data from PNSUS and the last 55 days (55B) of data for each coded theme.

Table 2

Theme Development Based upon Qualitative Data Analysis

\begin{tabular}{cccc}
\hline $\begin{array}{c}\text { Identifier } \\
\text { (Classroom/Student) }\end{array}$ & $\begin{array}{c}\text { Two weeks } \\
\text { preintervention }\end{array}$ & $\begin{array}{c}\text { Midpoint of } \\
\text { intervention }\end{array}$ & $\begin{array}{c}\text { Two weeks } \\
\text { postintervention }\end{array}$ \\
\hline A1 & $\mathrm{T}$ & $\mathrm{T}$ & $\mathrm{T}$ \\
$\mathrm{A} 2$ & & & $\mathrm{G}$ \\
$\mathrm{A} 3$ & & $\mathrm{~B}$ & $\mathrm{~B}$ \\
\hline
\end{tabular}


Table 3

Classroom A: Day 1 to Day 55 of Intervention: Coded Totals Excerpt

\begin{tabular}{|c|c|c|c|c|}
\hline$B$ & $T$ & $\mathrm{~S}$ & $G$ & $A$ \\
\hline $\begin{array}{l}\text { Day 1-55 } \\
\text { behavior }\end{array}$ & $\begin{array}{l}\text { Day 1-55 } \\
\text { teacher }\end{array}$ & $\begin{array}{l}\text { Day } 1-55 \\
\text { self-sent }\end{array}$ & $\begin{array}{c}\text { Day 1-55 } \\
\text { group }\end{array}$ & $\begin{array}{c}\text { Day 1-55 } \\
\text { aggression }\end{array}$ \\
\hline 1 & 0 & 0 & 0 & 0 \\
\hline 4 & 6 & 0 & 0 & 0 \\
\hline 0 & 0 & 0 & 0 & 0 \\
\hline 0 & 0 & 0 & 0 & 0 \\
\hline 7 & 31 & 7 & 1 & 1 \\
\hline 6 & 6 & 3 & 0 & 2 \\
\hline 1 & 8 & 2 & 0 & 2 \\
\hline 0 & 2 & 0 & 0 & 0 \\
\hline 0 & 1 & 1 & 0 & 0 \\
\hline 0 & 0 & 0 & 0 & 0 \\
\hline 1 & 14 & 1 & 1 & 0 \\
\hline 2 & 2 & 3 & 1 & 0 \\
\hline 3 & 5 & 3 & 0 & 1 \\
\hline 25 & Tot & Tot & Tot & Tot \\
\hline
\end{tabular}

Note. Days refer to number of days of data provided by PNSUS

Table 4

Classroom A: Day 55 to Day 110 of Intervention: Coded Totals Excerpt

\begin{tabular}{|c|c|c|c|c|}
\hline$B$ & $\mathrm{~T}$ & $S$ & $G$ & $A$ \\
\hline $\begin{array}{c}\text { Day } 55-110 \\
\text { behavior }\end{array}$ & $\begin{array}{c}\text { Day } 55-110 \\
\text { teacher }\end{array}$ & $\begin{array}{c}\text { Day } 55-110 \\
\text { self-sent }\end{array}$ & $\begin{array}{c}\text { Day } 55-110 \\
\text { group }\end{array}$ & $\begin{array}{l}\text { Day } 55-110 \\
\text { aggression }\end{array}$ \\
\hline 0 & 0 & 0 & 0 & 0 \\
\hline 1 & 0 & 0 & 1 & 0 \\
\hline 0 & 0 & 0 & 0 & 0 \\
\hline 0 & 0 & 0 & 0 & 0 \\
\hline 3 & 19 & 3 & 5 & 0 \\
\hline 3 & 4 & 0 & 0 & 0 \\
\hline 4 & 3 & 1 & 0 & 0 \\
\hline 0 & 0 & 0 & 0 & 0 \\
\hline 0 & 0 & 0 & 0 & 0 \\
\hline 0 & 0 & 0 & 0 & 0 \\
\hline 0 & 11 & 1 & 2 & 0 \\
\hline 1 & 3 & 0 & 1 & 0 \\
\hline 0 & 2 & 0 & 2 & 0 \\
\hline Tot & Tot & Tot & Tot & Tot \\
\hline 12 & 42 & 5 & 11 & 0 \\
\hline
\end{tabular}

Note. Days refer to number of days of data provided by PNSUS 
The following tables indicate the descriptive statistics on the combined group (all five classes), the control group (Classes $D$ and $E$ ), and the treatment group (Classes $A-C$ ), respectively. Table 5 contains the descriptive statistics of the combined control and treatment groups $(N=58)$ and revealed a decrease in all five incident types. The greatest percentage decrease in the combined group was evident in the frequency of self-sent occurrences, which dropped from 45 to 12 , a reduction of $73.33 \%$. The greatest decrease in occurrences of combined group was in the teacher sent frequency, which dropped from 162 to 99, a reduction of 63 occurrences. The average percentage change in frequencies across all incident types was a reduction of $49.53 \%$.

Table 5

Descriptive Statistics: Combined Groups (Control and Treatment)

\begin{tabular}{lccccc}
\hline \multicolumn{1}{c}{ Incident type } & $N$ & Min & Max & Sum & \% change \\
\hline 55A behavioral & 58 & 0 & 7 & 67 & \\
55B behavioral & 58 & 0 & 4 & 28 & $(58.21)$ \\
55A teacher & 58 & 0 & 31 & 162 & \\
55B teacher & 58 & 0 & 19 & 99 & $(38.00)$ \\
55A self-sent & 58 & 0 & 7 & 45 & \\
55B self-sent & 58 & 0 & 3 & 12 & $(73.33)$ \\
55A group & 58 & 0 & 3 & 20 & \\
55B group & 58 & 0 & 5 & 19 & $(5.00)$ \\
55A aggression & 58 & 0 & 4 & 18 & \\
55B aggression & 58 & 0 & 3 & 5 & $(72.22)$ \\
\hline Total participants combined & 58 & & & Avg +/- & $(49.53)$ \\
\hline
\end{tabular}

Table 6 contains the descriptive statistics of the treatment group, including 33 individual students, and revealed a decrease in four of five incident types from 55A to 55B of the case study. The frequency of group incidents was the only one that did not decrease from the first half of intervention to the second half; instead, it increased from 12 to 15 , an increase of $25 \%$. The greatest percentage decrease in the treatment group was in the frequency of aggressive incidents, which dropped from 14 to 1, a reduction of $92.86 \%$. The greatest decrease in occurrences was in the teacher sent frequency, which dropped from 116 to 63 , a reduction of 53 occurrences. The average change in frequencies was a reduction of $52.45 \%$ across all incident types.

Table 7 contains the descriptive statistics of the combined control group, including 25 individual students, and revealed a decrease in four of five incident themes from the first half to the second half of intervention. Aggressive incidents did not decrease, but remained the same between the first half and the second half of intervention at four. The greatest percentage decrease in the control group was evident in the self-sent frequencies, which dropped from 8 to 2, a reduction of 75\%. The greatest decrease in occurrences was in the teacher behavioral frequency, which dropped from 26 to eight. 
Table 6

Descriptive Statistics: Treatment Group

\begin{tabular}{lccccc}
\hline \multicolumn{1}{c}{ Incident type } & $N$ & Min & Max & Sum & \% change \\
\hline 55A behavioral & 33 & 0 & 7 & 41 & \\
55B behavioral & 33 & 0 & 4 & 20 & $(51.22)$ \\
55A teacher & 33 & 0 & 31 & 116 & \\
55B teacher & 33 & 0 & 19 & 63 & $(45.69)$ \\
55A self-sent & 33 & 0 & 7 & 37 & \\
55B self-sent & 33 & 0 & 3 & 10 & $(72.97)$ \\
55A group & 33 & 0 & 3 & 12 & \\
55B group & 33 & 0 & 5 & 15 & 25.00 \\
55A aggression & 33 & 0 & 4 & 14 & \\
55B aggression & 33 & 0 & 1 & 1 & $(92.86)$ \\
\hline Total participants treatment & 33 & & & Avg $+/-$ & $(47.55)$ \\
\hline
\end{tabular}

Table 7

Descriptive Statistics: Control Group

\begin{tabular}{lccccc}
\hline & $N$ & Min & Max & Sum & \% Change \\
\hline 55A behavioral & 25 & 0 & 7 & 26 & \\
55B behavioral & 25 & 0 & 2 & 8 & $(69.23)$ \\
55A teacher & 25 & 0 & 11 & 46 & \\
55B teacher & 25 & 0 & 10 & 36 & $(21.74)$ \\
55A self-sent & 25 & 0 & 2 & 8 & \\
55B self-sent & 25 & 0 & 2 & 2 & $(75.00)$ \\
55A group & 25 & 0 & 2 & 8 & \\
55B group & 25 & 0 & 1 & 4 & $(50.00)$ \\
55A aggression & 25 & 0 & 1 & 4 & \\
55B aggression & 25 & 0 & 3 & 4 & 0.00 \\
\hline Total participants control & 25 & & & Avg +/- & $(43.19)$ \\
\hline
\end{tabular}

Table 8 indicates the total number of incidents across all groups comparing the first half and the second half of the intervention. According to the study results, there was a $47.76 \%$ decrease in frequency of 149 incidents, down from 312 to 163. 
Table 8

Total Frequency of Incidents for Treatment and Control Groups

\begin{tabular}{lllccc}
\hline & $N$ & M & Max & Sum & \% change \\
\hline 55A (Day 1-55) & 58 & 0 & 47 & 312 & \\
55B (Day 55-110) & 58 & 0 & 30 & 163 & \\
Total participants & 58 & & & & $(47.76)$ \\
\hline
\end{tabular}

Dependent paired-sample $t$ tests were performed. The results are illustrated in Table 9. The $t$ tests revealed significant decreases in frequency of behavior, teacher sent, and aggression incidents. The only decrease that was not significant from the first half of the study to the second half was the frequency of group incidents reported.

Table 9

Paired-Sample t Tests

\begin{tabular}{lllll}
\hline \multicolumn{1}{c}{ Category (55A-55B) } & $M D$ & $S D$ & $t$ & $p$ \\
\hline 55A to 55B behavior & 0.67 & 1.72 & 2.98 & .004 \\
55A to 55B teacher & 1.09 & 2.44 & 3.39 & .001 \\
55A to 55B self-sent & 0.57 & 1.22 & 3.56 & .001 \\
55A to 55B group & 0.03 & 1.00 & 0.13 & .896 \\
55A to 55B aggression & 0.22 & 0.82 & 2.09 & .041 \\
\hline 55A to 55B - Total & 2.57 & 3.70 & 5.29 & .000 \\
\hline
\end{tabular}

\section{Additional Qualitative Data}

PNSUS provided meeting notes from two middle school teacher meetings. The first meeting took place at the end of the first 55 days, and the second meeting took place at the end of the second 55 days. The meeting notes were redacted and did not include identifying staff or student information. Feedback from several teachers noted the value and knowledge gained from the emergent in-service. Teachers requested additional in-services and the chance to spend more time learning about the concept and develop lesson plans within the group. Teachers expressed that the students were eagerly participating in the emergence theory-based lesson plans and that attempting to teach these skills to the students was an "eye-opening experience [because] it made it possible to see how these deficits effected all aspects of their lives" (Middle School Staff Meeting Summary Notes, March 10, 2014). Teachers remarked that having an "alternative curriculum with lesson plans targeting specific skills seemed to be more engaging and effective as compared to broader lesson topics" (Middle School Staff Meeting Summary Notes, March 10, 2014). 
Teacher feedback also included observations of the differences in the way some students were handling conflict resolution, as well as their general feelings about the progress that the middle school students were making. The comments did not indicate or differentiate between students within the treatment or control groups, so no meaningful conclusions between groups could be drawn from the meeting notes. Several positive comments were noted regarding the emergence theory-based curriculum. Feedback highlighted the importance that the teachers placed on understanding the cognitive deficits that the students exhibited, specifically in relation to their inability to compromise and see alternate perspectives. Teacher feedback did not include any negative feedback regarding the implementation of the emergence theory-based curriculum.

\section{Quantitative Analysis}

The quantitative data received from the school was an Excel spreadsheet that held the participating students' identifying information, pretest scores, and posttest scores. The total pretest and posttest scores were the sums of the scores of five subsections of the TOPS 2 defined by the test publisher and measuring the following critical-thinking skills:

- Subtest A: Making inferences.

- Subtest B: Determining solutions.

- Subtest C: Problem solving.

- Subtest D: Interpreting perspectives.

- Subtest E: Transferring insights.

These categories were respectively labeled subcategory $A, B, C, D$, and $E$ for data collection and reporting. Identifying data in the excerpt (see Table 10) were redacted.

ANCOVA was chosen as the statistical analysis tool, using pretest scores as the covariate and the groups as the factor. ANCOVA tests the assumptions of independence and normality (Salkind \& Green, 2011). The first step before conducting ANCOVA is to determine the homogeneity of slope assumption (Salkind \& Green, 2011). The test evaluates the interaction between the covariate (pretest scores) and the IV (control or treatment group) in the effect of the dependent variable (DV; posttest scores). The null hypothesis is conceptualized by there being little to no significant interaction between the covariate and the factor.

The aggression assumption was performed on the data; the results (see Table 11) indicated a significant interaction between the pretest scores and the control group or the treatment group, suggesting that the differences on the posttest scores varied as a function of the pretest scores, not treatment. The results of the regression assumption analysis showed a significant interaction between the pretest scores and the independent variable (IV), $F(2,51)=33.901, p<.001$. Therefore, ANCOVA was not appropriate and could not be used for further analysis. Additional analysis was performed by running a repeated-measures ANOVA. These results were not significant. 
Table 10

Excerpt of Pretest Data

\begin{tabular}{lcccccccc}
\hline & & & Pre & Pre & Pre & Pre & Pre & Pre \\
& & & A & B & C & D & E & Tot \\
\cline { 3 - 8 } Classroom A (one of the classes & Student & Student & & & & & & 0 \\
that received the treatment) & class & \# & & & & & & \\
\hline & A & 1 & 6 & 4 & 6 & 6 & 7 & 29 \\
& A & 2 & 5 & 4 & 3 & 7 & 6 & 25 \\
& A & 3 & 6 & 3 & 3 & 7 & 3 & 22 \\
& A & 4 & 4 & 3 & 4 & 6 & 7 & 24 \\
& A & 5 & 3 & 4 & 3 & 6 & 4 & 20 \\
& A & 6 & 4 & 2 & 2 & 5 & 2 & 15 \\
& A & 7 & 6 & 3 & 5 & 7 & 6 & 27 \\
& A & 8 & 6 & 4 & 3 & 6 & 7 & 26 \\
& A & 9 & 6 & 7 & 6 & 8 & 7 & 34 \\
& A & 10 & 7 & 8 & 5 & 6 & 6 & 32 \\
& A & 11 & 7 & 5 & 4 & 8 & 6 & 30 \\
& A & 12 & 6 & 6 & 6 & 5 & 5 & 28 \\
& A & 13 & 3 & 6 & 6 & 7 & 4 & 26 \\
\hline
\end{tabular}

Table 11

Regression Assumption: Tests of Between-subjects Effects

\begin{tabular}{|c|c|c|c|c|c|c|}
\hline \multicolumn{7}{|c|}{ Between-subjects factors } \\
\hline \multirow{3}{*}{ GROUP } & \multirow[b]{2}{*}{.0} & Value label & & \multicolumn{2}{|l|}{$N$} & \\
\hline & & \multicolumn{2}{|l|}{ Control } & \multicolumn{2}{|l|}{23} & \\
\hline & 1.0 & \multicolumn{2}{|l|}{ Treatment } & \multicolumn{2}{|l|}{31} & \\
\hline \multicolumn{7}{|c|}{ DV: POST_TOT } \\
\hline \multicolumn{2}{|l|}{ Source } & Type III SS & $d f$ & $M S$ & $F$ & Sig. \\
\hline \multicolumn{2}{|c|}{ Corrected Model } & $1445.814^{\mathrm{a}}$ & 2 & 722.907 & 33.901 & .000 \\
\hline \multicolumn{2}{|c|}{ Intercept } & 105.115 & 1 & 105.115 & 4.929 & .031 \\
\hline \multicolumn{2}{|c|}{ GROUP * PRE_TOT } & 1445.814 & 2 & 722.907 & 33.901 & .000 \\
\hline \multicolumn{2}{|l|}{ Error } & 1087.520 & 51 & 21.324 & & \\
\hline \multicolumn{2}{|l|}{ Total } & 28934.000 & 54 & & & \\
\hline \multicolumn{2}{|c|}{ Corrected total } & 2533.333 & 53 & & & \\
\hline
\end{tabular}

Note. a. $R^{2}=.571\left(\operatorname{Adj} R^{2}=.554\right)$ 
As part of the repeated measures analysis, a between-subject ANOVA without regard to the withinsubject effect was performed. These average scores were then compared between the treatment and control groups (see Table 12). These results were significant, $F(2,52)=9.107, p=.004$. Although this test did not account for groupings, it did indicate a significant difference between the average pretesting and posttesting score totals of the control group per participant and treatment group per participant.

Table 12

Tests of Between-Subjects Effects Without Regard to Within-Subjects Effects

Measure: MEASURE_1

Transformed variable: Average (Pretesting and posttesting score average per participant)

\begin{tabular}{lcccccc}
\hline \multicolumn{1}{c}{ Source } & Type III SS & $d f$ & MS & $F$ & Sig. & Partial $\eta$ \\
\hline Intercept & 61380.740 & 1 & 61380.740 & 789.029 & .000 & .938 \\
GROUP & 708.444 & 1 & 708.444 & 9.107 & .004 & .149 \\
Error & 4045.223 & 52 & 77.793 & & & \\
\hline
\end{tabular}

Descriptive statistics were performed on the pretesting and posttesting scores for the control and treatment groups. Table 13 shows that the scores for both groups dropped from pretest to posttest. The mean control group scored fell from 28.217 to 25.174 , with a standard deviation of 5.2824 pretest and 5.2105 posttest. The mean treatment group score fell from 23.194 to 19.839 , with a standard deviation of 8.1052 pretest and 7.2115 posttest. Expected results would be either no change or an increase in testing scores from pretest to posttest for both the control group and the treatment group. One possible reason for scores dropping from pretest to posttest was that PNSUS did not use the same person to administer the pretesting and posttesting.

Table 13

Descriptive Statistics

\begin{tabular}{lllll}
\hline & \multicolumn{1}{c}{ Group } & $M$ & $S D$ & $N$ \\
\hline \multirow{3}{*}{ Pretest } & Control & 28.217 & 5.2825 & 23 \\
& Treatment & 23.194 & 8.1052 & 31 \\
& Total & 25.333 & 7.4200 & 54 \\
\multirow{3}{*}{ Posttest } & Control & 25.174 & 5.2106 & 23 \\
& Treatment & 19.839 & 7.2115 & 31 \\
& Total & 22.111 & 6.9137 & 54 \\
\hline
\end{tabular}




\section{CONCLUSION}

In this case study, the merits of an emergence theory-based curriculum were assessed as one way to teach students with ASD how to compromise and see alternate perspectives. The triangulation of the literature review, qualitative feedback, and quantitative data indicated both the potential of emergence theory-based curriculum and a need for additional Professional Development (PD) focusing on implementation of emergence theory-based curriculum for use with students with ASD and related social and communication disorders. PD for teachers is important to the success of implementing new curriculum (Gibson \& Brooks, 2012). Effective Professional Development Workshops (PDWs) facilitate the use of new instructional practices and allow teachers to develop and construct knowledge. PDW are suitable to meet the primary goals of training teachers in emergence theory-based curriculum, giving them the skills necessary to implement lesson plans based upon emergence theory, providing them with a better understanding of ASD, and facilitating collaboration with colleagues.

There is a critical shortage of teachers who have been trained and are prepared to work with the rapidly growing population of students with ASD. Davis (2013) studied the factors affecting students with ASD in the mainstream education classroom and found the majority of teachers who have students with ASD in their classrooms have had minimal or no training to work with this student population. Helping teachers to implement evidence-based practices for students with ASD is an educational priority. Although additional research is necessary, emergence theory-based curriculum has the potential to help remediate ASD deficits.

Research indicated the lack of training and effective PD opportunities has led to many students with ASD leaving school without the requisite skills needed for success in the real world, including living independently, finding employment, or continuing their education. Higginson and Chatfield (2012) identified the nonacademic benefits of PD, noting that the knowledge gained from participating in the PD changed the teachers' attitudes about their observations of and interventions in the behaviors of students with ASD within the classroom. Prior to attending the PD, the teachers had attributed behaviors to the children being naughty or to bad parenting practices. After attending the PD, the teachers identified these same behaviors as consistent with a diagnosis of ASD and implemented new interventions rather than punitive consequences.

There is a need to improve the education provided to students with ASD, specifically in regard to the skills that they need to be successful beyond the classroom. Effective PD extends beyond academic progress in the classroom. Students with ASD educated by teachers who have been properly trained exhibit less anxiety, develop a positive attitude toward school, and demonstrate better home and social skills than students with ASD educated by poorly trained teachers.

The literature review and feedback from teachers at PNSUS identified a lack of knowledge and training for teachers working with students with ASD. In particular, the teachers at PNSUS requested additional training in emergence theory-based curriculum. PNSUS caters to students with ASD and related social and communication deficits. The staff at PNSUS receive far more training than their mainstream counterparts regarding ways to deal with students with ASD (PNSUS principal, personal communication, May, 2014). If PNSUS staff are requesting additional PD in emergence theory-based curriculum and 
lesson plan design, it is likely that an equal, if not greater, need for this PDW exists in the general teaching population, especially among teachers who work with students with ASD.

There is potential for social change beyond the campus of PNSUS. Bölte et al. (2014) found a direct correlation between cognitive skill levels and neurodevelopmental disorders, specifically, ASD and ADHD. An emergence theory-based curriculum which remediates these cognitive skills in children, adolescents, and adults diagnosed with ASD and related social and communication deficits could be instrumental in formulating alternative interventions and increasing the chance of long term success for these growing populations.

\section{REFERENCES}

Ablowitz, R., \& Goldstein, J. (2010). The theory of emergence. Emergence: Complexity \& Organization, 12(3), 133-154.

American Psychiatric Association. (2012). Diagnostic and statistical manual of mental disorders ( $5^{\text {th }}$ ed.). Washington, DC: Author.

Butt, T. (2008). The emergence of self in relationship. Existential Analysis: Journal of the Society for Existential Analysis, 19(1), 102-112. Retrieved from PsycINFO database.

Centers for Disease Control and Prevention. (2013). Autism spectrum disorder (ASD). Retrieved from http://www.cdc.gov/

Creswell, J. W. (2012). Educational research: Planning, conducting, and evaluating quantitative and qualitative research $\left(4^{\text {th }}\right.$ ed.). Boston, MA: Pearson.

Davis, A. (2013). Factors that impact a child on the autism spectrum in the general education classroom. Retrieved from ERIC database.

Ferlazzo, L. (2011). The art \& importance of compromise. Retrieved from http:// larryferlazzo.edublogs.org/

Fletcher-Watson, S., McConnell, F., Manola, E., \& McConachie, H. (2014). Interventions based on the theory of mind cognitive model for autism spectrum disorder (ASD). Cochrane Database of Systematic Reviews. doi:10.1002/14651858.CD008785. pub2

Gibson, S. E., \& Brooks, C. (2012). Teachers' perspectives on the effectiveness of a locally planned professional development program for implementing new curriculum. Teacher Development, 16(1), 1-23. Retrieved from ERIC database.

Goldstein, J. (1999). Emergence as a construct: History and issues. Emergence, 1(1), 49-72. doi:1207/s15327000em0101_4

Healy, E. M. (2008). Improving autism policies beyond the enigma: Current challenges and future considerations for improving policies to support individuals living with autism. Speaker's Journal, 8(14), 141-156. Retrieved from REM SPEC EDUC database.

Henry, G. T. (2000). Practical sampling: Applied social research methods series. Newbury Park, CA: SAGE. 
Higginson, R., \& Chatfield, M. (2012). Together we can do it: A professional development project for regular teachers of children with autism spectrum disorder. Kairaranga, 13(2), 29-40. Retrieved from ERIC database.

Hodgetts, S. (2011). Effects of weighted vests on classroom behavior for children with autism and cognitive impairments. Research in Autism Spectrum Disorders, 5(1), 495-505.

Horrocks, J. L., White, G., \& Roberts, L. (2008). Principals' attitudes regarding inclusion of children with autism in Pennsylvania public schools. Journal of Autism and Developmental Disorders, 38(8), 1462-1473. Retrieved from CINAHL database.

Hotton, S., \& Yoshimi, J. (2011). Extending dynamical systems theory to model embodied cognition. Cognitive Science, 35, 444-479. Retrieved from PsycINFO database.

Hui Min, L., \& Lay Wah, L. (2011). Teaching of speech, language, and communication skills for young children with severe autism spectrum disorders: What do educators need to know? New Horizons in Education, 59(3), 16-28. Retrieved from ERIC database.

Huisingh, R., \& LoGiudice, C. (2005). Test of Problem Solving 3 - Elementary test. Retrieved from www.asha.org/

Hussin, S., Cheong, L. S., \& Ai Hwa, Q. (2012). Overcoming the challenge of inclusion through smart initiatives: A case study. Journal of Special Needs Education, 2, 51-82. Retrieved from http://www.myjurnal.my/

Jones, A. P., \& Frederickson, N. (2010). Multi-informant predictors of social inclusion for student with autism spectrum disorders attending mainstream schools. Juvenile Autism Developmental Disorders, 40, 1094-1103. Retrieved from ERIC database.

Lawhon, T., \& Lawhon, D. C. (2000). Promoting social skills in young children. Early Childhood Education Journal, 28(2), 105-110. doi:10.1023/A:1009551404906

Mandell, D. S., Coa, J., Ittenback, R., \& Pinto-Marin, J. (2006). Medicaid expenditures for children with autistic spectrum disorders: 1994 to 1999. Journal of Autism and Developmental Disorders, 36(4), 475-485. Retrieved from CINAHL database.

Morrier, M., Hess, K., \& Heflin, L. (2011). Teacher training for implementation of teaching strategies for students with autism spectrum disorders. Journal of Teacher Education: Division of the Council for Exceptional Children, 34(2), 119-132. Retrieved from ERIC database.

Morris, K. M. (2008). A better future for children with autism, Asperger's syndrome and related developmental disorders. Retrieved from www.autism-help.org/

Piaget, J. (1951). Principal factors determining intellectual evolution from childhood to adult life. In D. Rapaport (Ed.), Organization and pathology of thought: Selected sources (pp. 154-175). New York, NY: Columbia University Press. doi:10.1037/ 10584-006

Quill, K. A. (1995). Strategies to enhance communication and socialization. New York, NY: Delmar. 
Rucklidge, J. R. (2009). Successful treatment of OCD with a micronutrient formula following partial response to cognitive behavioral therapy (CBT): A case study. Journal of Anxiety Disorders, 23(6), 836-840. Retrieved from CINAHL database.

Salkind, N. J., \& Green, S. B. (2011). Using SPSS for Windows and Macintosh (6 ${ }^{\text {th }}$ ed.). Boston, MA: Prentice Hall.

Skinner, B. F. (1977). Herrnstein and the evolution of behaviorism. American Psychologist, 32(12), 10061012. doi:10.1037/0003-066X.32.12.1006

Szameitat, A. J., Raabe, M., Müller, H. J., Greenlee, M. W., Mourão-Miranda, J., Goltz, D., ... Tsankova, E. (2010). Motor imagery of voluntary coughing - A functional MRI study using a support vector machine. NeuroReport, 21(15), 980-984. doi:10.1097/WNR.0b013e32833e926f

U.S. Department of Education. (2004). Building the legacy: IDEA 2004. Retrieved from http://idea.ed.gov/

Van Roekel, E. (2010). Bullying among adolescents with autism spectrum disorders: Prevalence and perception. Journal of Autism and Developmental Disorders, 40(1), 63-73. doi:10.1007/s10803009-0832-2

Vygotsky, L., \& Vygotsky, S. (1980). Mind in society: The development of higher psychological processes. Cambridge, MA: Harvard University Press.

Yeargin-Allsopp, M. (2003). Prevalence of autism in a US metropolitan area. Journal of American Medical Association, 289(1), 49-55. Retrieved from http://www.cdc.gov/

Yin, R. K. (2005). Introducing the world of education: A case study reader. Thousand Oaks, CA: SAGE.

Yin, R. K. (2009). Case study research ( $4^{\text {th }}$ ed.). Thousand Oaks, CA: SAGE.

\section{ABOUT THE AUTHORS}

Dr. Lance Fein (Lance.Fein@Waldenu.edu) is currently the Executive Director of Alternative Education Foundation (AEF). Dr. Fein has experience working with remedial and special education populations. He has founded several special needs programs and has served as Director for both day and residential programs catering to children with special needs. His areas of interest include instructional technology, behavior modification strategies, and psychopharmacology. Correspondence may be directed to Lance Fein, Ed.D., Walden University, 4650 SW 61st Ave, Fort Lauderdale, FL 33314. Phone: +011 954-5818222

Dr. Don Jones (Don.Jones@tamuk.edu) currently serves as a professor of education in the Ed.D. Program at Texas A\&M University-Kingsville. His background includes extensive experience in higher education leadership, as well as public school administration, including service as an elementary principal, high school principal and in the superintendency. His areas of interest include philosophy, ethics, leadership and school board training and development. Correspondence maybe directed to Don Jones, Ed.D., Assistant Professor of Educational Leadership, Texas A\&M University - Kingsville, 6266 Strasbourg Dr., Corpus Christi, TX, 78414. Phone: +011 361-522-0401 